\title{
An Examination of the Triarchic Conceptualization of Psychopathy in Incarcerated and Nonincarcerated Samples
}

\author{
Martin Sellbom \\ University of Alabama
}

\author{
Tasha R. Phillips \\ Wright State University
}

\begin{abstract}
The current study tested hypotheses associated with the triarchic conceptualization of psychopathy (Patrick, 2010b; Patrick, Fowles, \& Krueger, 2009), which describes three distinctive, albeit related, phenotypic domains-boldness, meanness, and disinhibition. We used two samples consisting of 209 female prison inmates and 627 undergraduate students whom had been administered a range of psychopathy and psychopathy-relevant measures. Our results indicated that the triarchic domains explained variance in other psychopathy models to degrees consistent with conceptual expectations. We also examined associations between the triarchic domains and personality traits relevant to psychopathy in the female correctional sample. The results showed that boldness was preferentially associated with narcissism, thrill/adventure seeking, and low behavioral inhibition system functioning; meanness with Machiavellianism, low empathy, and low behavioral inhibition system; and disinhibition with impulsivity and fun seeking.
\end{abstract}

Keywords: psychopathy, triarchic, prisoners, college students
Psychopathic individuals are marked by features such as callousness, lack of remorse, and egocentricity, and are motivated by personal gain to manipulate, harm, and exploit others. In an effort to integrate historical and contemporary accounts of psychopathy, including as manifested via common measurement modalities in both youth and adulthood, Patrick (2010b; Patrick et al. 2009) has elaborated on a triarchic conceptualization of psychopathy via three broad, phenotypic domains: boldness, meanness, and disinhibition.

Boldness represents the nexus of social dominance, thrill seeking/fearlessness, and low stress-reactivity (Patrick et al., 2009), and can be traced back to Cleckley's (1976) and Lykken's (1995) descriptions of psychopathy. As Patrick (2006) noted, several of Cleckley's descriptors can be organized as indicating positive psychological adjustment (e.g., good intelligence and social adeptness, absence of nervousness), reflecting immunity to internalizing psychopathology and fear; in other words, the presence of severe underlying behavioral pathology is masked by an outward appearance of robust mental health. At the measurement level, boldness has primarily been emphasized in the Psychopathic Personality Inventory (PPI; Lilienfeld \& Andrews, 1996), and revised version

This article was published Online First August 6, 2012.

Martin Sellbom, Department of Psychology, The University of Alabama; Tasha R. Phillips, Department of Psychology, Wright State University.

We thank the Ohio Department of Rehabilitation and Corrections for facilitating the collection of the correctional sample. We thank Yossef Ben-Porath and Brandee Marion for their assistance with various aspects of this project.

Correspondence concerning this article should be addressed to Martin Sellbom, Department of Psychology, 348 Gordon Palmer Hall, University of Alabama, Tuscaloosa, AL 35487-0348. E-mail: msellbom@ua.edu
(PPI-R; Lilienfeld \& Widows, 2005), particularly through a broad construct labeled Fearless-Dominance extracted via factor analysis of the PPI subscales (Benning, Patrick, Hicks, Blonigen, \& Krueger, 2003; but see Neumann, Malterer, \& Newman, 2008 for an opposing factor structure).

Meanness is best characterized as a phenotypic manifestation of reduced empathic responding, callousness, exploitativeness, empowerment through cruelty, inability to form close attachments with others, and excitement seeking (Patrick et al., 2009). It has historical roots in McCord and McCord's (1964) description of psychopaths as cold, vicious, and predatory individuals who are primarily motivated by rage. Presently, this view is best exemplified by Hare's (e.g., 1996, 2003) writings about psychopathy in adulthood, and as callous-unemotional traits in childhood (e.g., Barry et al., 2000). At the measurement level, the Psychopathy Checklist-Revised (PCL-R; Hare, 2003) and its derivatives, encompasses the meanness domain, particularly via the affective-interpersonal factor (PCL-R Factor 1; Patrick et al., 2009), as do the child and adolescent instruments focused on callous-unemotional traits (Antisocial Process Screening Device [APSD; Frick \& Hare, 2001]; Inventory of CallousUnemotional traits [ICU; Frick, 2004]). Self-report measurements of psychopathy, such as the PPI-R coldheartedness factor and the egocentricity and callous subscales from the Levenson Self-Report Psychopathy Scale (LSRP; Levenson, Kiehl, \& Fitzpatrick, 1995; Sellbom, 2011) are also hypothesized to reflect meanness from Patrick, Fowles, and Krueger's (2009) perspective.

Finally, disinhibition represents a propensity toward impulse control problems, including nonplanfulness, failure to delay gratification, irresponsibility, reactive angry emotionality, and deficient behavioral constraint (Patrick et al., 2009). This description can be traced back to most conceptual formulations of psychopa- 
thy (e.g., Cleckley, 1941/1976; Hare, 1996; McCord \& McCord, 1964). From the measurement perspective, virtually all psychopathy instruments cover this domain to some degree, including the PCL-R, PPI, APSD, and LSRP (Patrick, 2010b; Patrick et al., 2009).

To date, there is no published research available that has put the hypotheses underlying the triarchic conceptualization of psychopathy to an empirical test. Some studies have used the Externalizing Spectrum Inventory (Krueger, Markon, Patrick, Benning, \& Kramer, 2007) to elaborate on differences between meanness and disinhibition (Venables \& Patrick, 2011), whereas research using the PPI/PPI-R fearless-dominance measure has generated results that are relevant to boldness. However, no study has directly examined these three triarchic domains in conjunction or via any form of measurement that was designed to operationalize them, such as the Triarchic Psychopathy Measure (Patrick, 2010a) used in the current study.

The current investigation aimed to examine the triarchic conceptualization of psychopathy in both incarcerated and nonincarcerated samples. First, we examined the degree to which established psychopathy measures from different conceptual perspectives were associated with the boldness, meanness, and disinhibition domains in ways that would be predicted based on the triarchic model (Patrick, 2010b; Patrick et al., 2009). Second, we explored the latent factor structure of all psychopathy subscales to (a) determine the optimal number of latent factors that explain variance in these scales, and (b) whether three of those factors would be representative of the triarchic domains. Third, we examined the associations between the triarchic domains and psychopathy-relevant personality traits.

We hypothesized that boldness would primarily explain variance in the PPI-R fearless-dominance domain (Patrick et al., 2009), and be preferentially associated with narcissism, thrill and adventure seeking, and a hypoactive behavioral inhibition system given its conceptual link to reduced fear-activity at the personality trait level (cf. Lykken, 1995; Patrick et al., 2009). We further hypothesized that meanness would explain variance in the PPI-R coldheartedness factor (cf. Marcus, Fulton, \& Edens, 2012), the LSRP egocentricity and callous subfacets (Sellbom, 2011), as well as the ICU and the APSD callousunemotional facet (Patrick et al., 2009). We also expected that meanness would be linked to low empathy, Machiavellianism, excitement seeking, and a low behavioral inhibition system, based on the hypothesis that boldness and meanness share a fearless temperament (Patrick et al., 2009). Finally, disinhibition was hypothesized to explain variance in subscales from all psychopathy measures used in this study, including the PPI/ PPI-R self-centered impulsivity, LSRP antisocial, and APSD impulsive and narcissism factors (Patrick et al., 2009), as well as be meaningfully related to the impulsivity aspects of sensation seeking and behavioral activation system (Marcus et al., 2012).

\section{Method}

\section{Participants and Procedures}

Correctional sample. Participants were 271 female inmates incarcerated at a midwestern state correctional facility deemed eligible based on having a minimum eighth grade reading level per the Comprehensive Adult Student Assessment System Reading Test. They were screened for inconsistent responding using Minnesota Multiphasic Personality Inventory (MMPI)-2-RF (BenPorath \& Tellegen, 2008) validity scales (VRIN-r and TRIN-r T $\geq$ $80)$, which led to the exclusion of 62 participants. The final sample $(n=209)$ ranged in age from 18 to 61 years $(M=27.47, S D=$ $2.45)$, and were mostly Caucasian $(80 \%)$ or African American $(19 \%)$. The most frequent charges were homicide-related $(27 \%)$, other violent offenses (19\%), drug-related (17\%), and theft-related offenses (15\%).

College sample. Participants were 777 undergraduate students screened for inconsistent responding using MMPI-2-RF validity scales (VRIN-r and TRIN-r T $\geq 80$ ); this led to the exclusion of 150 participants. The final sample consisted of 204 men and 423 women, who ranged in age from 17 to 40 years $(M=19.05, S D=$ 1.73). They were Caucasian (84\%), African American (11\%), or from other or mixed ethnic backgrounds $(5 \%)$.

\section{Measures-Both Samples}

Internal consistency reliability estimates for all scales and subscales (except TriPM scales; see below) used for analyses are listed in Tables 1 or 3.

Triarchic Personality Measure. The TriPM (Patrick, 2010a) is a 58-item self-report inventory of psychopathy. Participants respond to each item on a 4-point Likert scale $(1=$ true, $2=$ mostly true, $3=$ mostly false, $4=$ false). It does not yield a total score, but rather three domain scores, representing boldness, meanness, and disinhibition. Internal consistency reliability estimates were .89/.82 (correctional/college) for boldness, .90/.88 for meanness, and $.89 / .84$ for disinhibition.

Psychopathic Personality Inventory/Psychopathic Personality Inventory-Revised. The 187-item PPI (Lilienfeld \& Andrews, 1996) and the 154-item PPI-R (Lilienfeld \& Widows, 2005) were administered in the correctional and college sample, respectively. These self-report inventories measure various personality features associated with historical conceptualizations of psychopathy (e.g., Cleckley, 1941/1976; Karpman, 1941). Both versions yield one total score, three factor scores: fearless-dominance, impulsive antisociality (self-centered impulsivity on the PPI-R) and coldheartedness (based on one single subscale), and scores from eight subscales: Social potency (social influence on the PPI-R), fearlessness, stress immunity, Machiavellian egocentricity, impulsive nonconformity (rebellious nonconformity on the PPI-R), blame externalization, carefree nonplanfulness, and coldheartedness.

Levenson's Self-Report Psychopathy Scale. The 26-item LSRP (Levenson et al., 1995) was designed to assess similar domains to the PCL-R. Recent research indicates that the LSRP measures three factors of psychopathy, egocentricity, callousness, and antisociality, with promising validity (e.g., Sellbom, 2011).

\section{Measures-Correctional Sample}

Emotional Empathy Scale. The EES (Mehrabian \& Epstein, 1972) is a 33-item scale designed to measure a person's reaction to and ability to vicariously experience the emotional 
Table 1

Correlation and Regression Analyses for Triarchic Domains Predicting Scores on Other Psychopathy Measures

\begin{tabular}{|c|c|c|c|c|c|c|c|c|c|}
\hline & \multicolumn{2}{|c|}{$\begin{array}{c}\text { Internal } \\
\text { consistency }\end{array}$} & \multicolumn{2}{|c|}{ Boldness } & \multicolumn{2}{|c|}{ Meanness } & \multicolumn{2}{|c|}{ Disinhibition } & \multirow[b]{2}{*}{$R^{2}$} \\
\hline & $\alpha$ & AIC & $r$ & $\beta$ & $r$ & $\beta$ & $r$ & $\beta$ & \\
\hline PPI total ${ }^{\mathrm{a}}$ & .96 & .14 & .38 & $.38^{*}$ & .64 & $.44^{*}$ & .48 & $.38^{*}$ & $.61^{*}$ \\
\hline PPI-R total ${ }^{\mathrm{b}}$ & .93 & .09 & .59 & $.47^{*}$ & .71 & $.37^{*}$ & .56 & $.37^{*}$ & $.75^{*}$ \\
\hline PPI fearless dominance ${ }^{\mathrm{a}}$ & .93 & .19 & .78 & $.79^{*}$ & .19 & .03 & -.03 & .09 & $.62^{*}$ \\
\hline PPI-R fearless dominance ${ }^{b}$ & .91 & .18 & .84 & $.81^{*}$ & .39 & .08 & .13 & .08 & $.72 *$ \\
\hline PPI self-centered impulsivity ${ }^{\mathrm{a}}$ & .95 & .19 & -.09 & -.08 & .58 & $.43^{*}$ & .60 & $.43^{*}$ & $.43^{*}$ \\
\hline PPI-R self-centered impulsivity ${ }^{b}$ & .90 & .12 & .16 & .05 & .62 & $.30^{*}$ & .74 & $.58^{*}$ & $.58^{*}$ \\
\hline PPI coldheartedness $\mathrm{s}^{\mathrm{a}}$ & .82 & .19 & .26 & .19 & .38 & $.37^{*}$ & .06 & -.04 & $.19^{*}$ \\
\hline PPI-R coldheartedness ${ }^{\mathrm{b}}$ & .81 & .21 & .24 & .00 & .67 & $.76^{*}$ & .22 & -.18 & $.47^{*}$ \\
\hline PPI Machiavellian egocentricity ${ }^{\mathrm{a}}$ & .92 & .26 & .08 & .05 & .67 & $.54 *$ & .52 & $.34^{*}$ & $.54^{*}$ \\
\hline PPI-R Machiavellian egocentricity & .84 & .21 & .20 & .03 & .67 & $.51^{*}$ & .53 & $.27^{*}$ & $.49^{*}$ \\
\hline PPI carefree nonplanfulness ${ }^{\mathrm{a}}$ & .87 & .25 & -.25 & -.22 & .33 & $.23^{*}$ & .52 & $.39^{*}$ & $.34^{*}$ \\
\hline PPI-R carefree nonplanfulness ${ }^{\mathrm{b}}$ & .81 & .18 & .02 & .02 & .38 & .10 & .59 & $.54^{*}$ & $.36^{*}$ \\
\hline LSRP total $^{\mathrm{a}}$ & .85 & .24 & .01 & -.04 & .65 & $.56^{*}$ & .50 & $.30^{*}$ & $.51^{*}$ \\
\hline LSRP total ${ }^{\mathrm{b}}$ & .86 & .25 & .14 & -.04 & .72 & $.57^{*}$ & .61 & $.31 *$ & $.60^{*}$ \\
\hline LSRP egocentricity ${ }^{\mathrm{a}}$ & .82 & .33 & .12 & .04 & .59 & $.55^{*}$ & .29 & .11 & $.36^{*}$ \\
\hline LSRP egocentricity ${ }^{b}$ & .84 & .34 & .18 & -.02 & .66 & $.61^{*}$ & .44 & .12 & $.45^{*}$ \\
\hline LSRP callous ${ }^{\mathrm{a}}$ & .74 & .41 & .01 & -.05 & .51 & $.46^{*}$ & .33 & .16 & $.29^{*}$ \\
\hline LSRP callous ${ }^{\mathrm{b}}$ & .67 & .33 & .17 & .00 & .63 & $.55^{*}$ & .44 & $.16^{*}$ & $.41^{*}$ \\
\hline LSRP antisocial ${ }^{\mathrm{a}}$ & .69 & .32 & -.18 & -.13 & .38 & $.24^{*}$ & .61 & $.50^{*}$ & $.42^{*}$ \\
\hline LSRP antisocial ${ }^{\mathrm{b}}$ & .67 & .28 & -.05 & -.09 & .40 & .13 & .64 & $.57^{*}$ & $.42^{*}$ \\
\hline Inventory of callous-unemotional traits & .82 & .16 & .11 & -.08 & .64 & $.60^{*}$ & .45 & .14 & $.44^{*}$ \\
\hline APSD total ${ }^{\mathrm{b}}$ & .78 & .15 & .20 & .08 & .65 & $.39^{*}$ & .66 & $.45^{*}$ & $.57^{*}$ \\
\hline APSD callous-unemotional $^{\mathrm{b}}$ & .42 & .12 & .07 & -.07 & .52 & $.41^{*}$ & .45 & $.23^{*}$ & $.32^{*}$ \\
\hline APSD narcissism ${ }^{\mathrm{b}}$ & .69 & .24 & .18 & .05 & .54 & $.42^{*}$ & .42 & .20 & $.32^{*}$ \\
\hline APSD impulsivity ${ }^{\mathrm{b}}$ & .59 & .22 & .12 & .11 & .36 & .03 & .58 & $.56^{*}$ & $.35^{*}$ \\
\hline
\end{tabular}

Note. Coefficients in bold were hypothesized. $r \mathrm{~s}=\mid .16 \mathrm{l}$ in the college sample and $\mid .23 \mathrm{I}$ in the correctional sample were statistically significant at $p<$ .0008. AIC $=$ Average Inter-Item Correction; PPI $=$ Psychopathic Personality Inventory; LSRP = Levenson Self-Report Psychopathy Scales; APSD = Antisocial Processes Screening Device-Youth Version.

${ }^{\mathrm{a}}$ Female correctional sample. ${ }^{\mathrm{b}}$ College sample.

$* p<.0008$.

states of others. Mehrabian and Epstein (1972) showed that those with lower EES scores were more willing to act aggressively (using both self-report and laboratory measures) than those with higher scores.

Emotionality-Activity-Sociability-Impulsivity Scale. The EASI (Buss \& Plomin, 1984) is a 25-item inventory developed to operationalize the four temperament traits of emotionality, activity, sociability, and impulsivity. Buss and Plomin (1984) provide substantial convergent and discriminant validity data of these scales.

Machiavellianism Inventory. The MACH-IV (Christie \& Geis, 1970) is a 20-item scale that measures attitudes and behaviors associated with the Machiavellian personality construct. This scale correlates moderately with psychopathy and narcissism (Paulhus \& Williams, 2002).

Narcissistic Personality Inventory. The NPI (Raskin \& Terry, 1988) consists of 40 items designed to measure the construct of DSM-III Narcissistic Personality Disorder (APA, 1980). This measure has been found to be highly associated with measures of interpersonal dominance and observer ratings of narcissism, self-confidence, and self-centeredness (Raskin \& Terry, 1988).

Behavioral Inhibition Scale/Behavioral Activation Scale. This BIS/BAS (Carver \& White, 1994) is a 24-item self-report measure. The BIS is designed to assess sensitivity to punishment and avoidance motivation, whereas the BAS is designed to assess sensitivity to reward and approach motivation. The BAS further has three specific scales reflecting fun seeking, drive, and reward responsivity. Jorm et al. (1998) presented substantial convergent and discriminant validity data on these scales in a very large community sample.

\section{Measures-College Sample}

Antisocial Processes Screening Device-Youth Version. The APSD (Frick \& Hare, 2001) is a 20-item self-report inventory designed to measure psychopathic traits in juveniles. It was developed as a downward extension of the PCL-R (Hare, 2003) to be filled out by an adult rating of an adolescent. We used the measure as a self-report inventory with altered wording for first-person responses, as other researchers have done in a valid manner (e.g., Caputo, Frick, \& Brodsky, 1999), including with college students (e.g., Neal \& Sellbom, 2012).

Inventory of Callous-Unemotional Traits. The ICU (Frick, 2004) is a 24-item self-report inventory of callous and unemotional traits for adolescents. The measure was developed as an improvement of the APSD Callous-Unemotional scale by adding 18 items and expanding the rating system for greater variability. Empirical research supports its validity of CU traits (e.g., Kimonis et al., 
2008), including when college students are used as participants (e.g., Neal \& Sellbom, 2012).

\section{Results $^{1}$}

\section{Psychopathy Measures}

We calculated zero-order correlations to test hypotheses regarding the degree to which the triarchic domains explain variance in various psychopathy measurements with differing conceptual underpinnings. Because of the number of correlations calculated, we used a conservative alpha of .0008 (.05/66 correlations in each sample, including those reported below) to determine statistical significance. Furthermore, to determine the triarchic domains scores' unique associations with other psychopathy measures, we also conducted multiple regression analyses in which each criterion variable was regressed onto the boldness, meanness, and disinhibition domain scores (see Table 1). At the zero-order level, psychopathy total and subscale scores were associated with the boldness (mdn. $r=.69$ ), meanness (mdn. $r=.65$ ), and disinhibition (mdn. $r=.59$ ) domains as theoretically expected. Nonhypothesized associations were substantially smaller (mdn. $r \mathrm{~s}=.12$ [boldness], .39 [meanness], and .39[disinhibition]). The regression results, which allowed for accounting for the overlap between the triarchic domains further clarified these associations. Boldness primarily explained variance in the PPI/PPI-R fearless dominance factor. Meanness captured unique variance in all of the psychopathy measures, and in particular factors and subscales reflecting coldheartedness, callousness, and self-centeredness. Disinhibition also explained variance in all psychopathy measures, as theoretically expected, and was preferentially associated with factor scores reflecting impulsivity and antisociality.

We also conducted analyses to better understand the sources of covariation for the PPI/PPI-R Self-Centered Impulsivity and the meanness versus disinhibition domains. We examined two specific subscales, Machiavellian egocentricity and carefree nonplanfulness, which conceptually would be core markers of callousaggression and impulsivity, respectively. As shown in Table 1, Machiavellian egocentricity, although correlated with disinhibition, was preferentially associated with meanness, whereas carefree nonplanfulness was primarily associated with disinhibition.

Finally, in the college sample, to further examine the triarchic model of psychopathy, we subjected the three domains scales and all of the subscales from other inventories (APSD-CU was not included due to its substantial item overlap with the ICU) to an exploratory factor analysis. Maximum likelihood estimation was used to extract the optimal number of factors in conjunction with parallel analysis. The first four eigenvalues from the actual data were $6.376,2.562,1.720$, and 1.185; the first four corresponding 95th percentile random data eigenvalues were 1.299, 1.238, 1.212, and 1.191, indicating retention of the first three factors for oblique rotation as the optimal solution. Table 2 shows the promax-rotated factor loadings for the psychopathy scales on the three factors. We adopted a minimum of $I .401$ as a significant loading. The pattern of loadings was strongly indicative of factors reflecting meanness (35.51\% of variance explained), disinhibition (15.07\% variance), and boldness $(10.11 \%$ variance explained). The correlations between resulting factors were .14 (boldness/disinhibition), .34 (boldness/meanness), and .54 (meanness/disinhibition), which
Table 2

Rotated Factor Loadings Based on Exploratory Factor Analysis With all Psychopathy Subscales in College Sample

\begin{tabular}{lccc}
\hline & $\begin{array}{c}\text { Meanness } \\
(35.51 \%)\end{array}$ & $\begin{array}{c}\text { Disinhibition } \\
(15.07 \%)\end{array}$ & $\begin{array}{r}\text { Boldness } \\
(10.11 \%)\end{array}$ \\
\hline PPI-R coldheartedness & $\mathbf{. 9 6}$ & -.34 & -.02 \\
TriPM meanness & $\mathbf{. 8 0}$ & .10 & .09 \\
Inventory of callous and & & & \\
$\quad$ unemotional traits & $\mathbf{. 7 2}$ & .10 & -.09 \\
LSRP callous & $\mathbf{. 6 8}$ & .10 & -.02 \\
LSRP egocentricity & $\mathbf{. 6 5}$ & .17 & -.01 \\
PPI-R Machiavellian & & & \\
$\quad$ egocentricity & $\mathbf{. 5 0}$ & .36 & .04 \\
APSD narcissism & $\mathbf{. 4 2}$ & .27 & .05 \\
TriPM disinhibition & .13 &. $\mathbf{7 6}$ & -.06 \\
LSRP antisocial & .01 & $\mathbf{. 7 6}$ & -.08 \\
APSD impulsivity & -.07 & $\mathbf{. 7 5}$ & .11 \\
PPI-R blame externalization & -.06 & $\mathbf{. 5 6}$ & -.11 \\
PPI-R rebellious nonconformity & -.04 & $\mathbf{. 5 6}$ & .28 \\
PPI-R carefree nonplanfulness & .18 & $\mathbf{. 5 5}$ & -.06 \\
TriPM boldness & -.02 & -.08 & $\mathbf{. 9 1}$ \\
PPI-R social potency & -.14 & .12 & $\mathbf{. 7 4}$ \\
PPI-R stress immunity & .23 & -.33 & $\mathbf{. 6 2}$ \\
PPI-R fearlessness & -.02 & .29 & $\mathbf{. 5 3}$ \\
\hline
\end{tabular}

Note. Rotated factor loadings greater than I.40I appear in bold. PPI-R $=$ Psychopathic Personality Inventory-Revised; TriPM = Triarchic Psychopathy Measure; LSRP = Levenson Self-Report Psychopathy Scale; APSD $=$ Antisocial Processes Screening Device - Youth Version.

conforms to Patrick et al.'s (2009) hypotheses concerning domainoverlap.

\section{Psychopathy-Relevant Personality Traits}

Next, we calculated zero-order correlations and regression equations to examine the associations between the triarchic domains and psychopathy-relevant personality constructs (see Table 3). In general, hypothesized associations were larger than those not hypothesized (mdn. $r \mathrm{~s}=.40$ vs. .12 [boldness], .41 vs. .17 [meanness], and .29 vs. 07 [disinhibition]). Meanness was the best predictor of Machiavellianism and low empathy, whereas boldness was the best predictor of narcissistic personality traits. The triarchic domains' association with sensation seeking revealed a somewhat unexpected pattern of associations. All three domains contributed about equally to the prediction of the SSS total score. Meanness was the best predictor of boredom susceptibility, and meanness and disinhibition were both associated with SSS disinhibition. Boldness, on the other hand, was the best predictor of both thrill and adventure seeking and experience seeking. Furthermore, boldness and disinhibition were both associated with BAS drive and fun seeking, though disinhibition was clearly the best predictor of the latter construct. As expected, boldness was the strongest predictor of BIS, but meanness was also uniquely and meaningfully related to this construct.

\footnotetext{
${ }^{1}$ We also examined mean differences on triarchic domains across three groups of college males, college females, and female inmates, but we do not show them here due to space limitations. These results are available upon request.
} 
Table 3

Correlation and Regression Analyses for Triarchic Domains With Psychopathy-Relevant Personality Traits in Female Correctional Sample

\begin{tabular}{|c|c|c|c|c|c|c|c|c|c|}
\hline & \multicolumn{2}{|c|}{$\begin{array}{c}\text { Internal } \\
\text { consistency }\end{array}$} & \multicolumn{2}{|c|}{ Boldness } & \multicolumn{2}{|c|}{ Meanness } & \multicolumn{2}{|c|}{ Disinhibition } & \multirow[b]{2}{*}{$R^{2}$} \\
\hline & $\alpha$ & AIC & $r$ & $\beta$ & $r$ & $\beta$ & $r$ & $\beta$ & \\
\hline Machiavellianism & .67 & .15 & -.19 & $-.26^{*}$ & .53 & $.54^{*}$ & .32 & .06 & $.36^{*}$ \\
\hline Empathy & .85 & .16 & -.26 & -.19 & -.40 & $-.41^{*}$ & -.03 & .08 & $.21^{*}$ \\
\hline Narcissism & .92 & .23 & .64 & $.64^{*}$ & .37 & $.20^{*}$ & .12 & .17 & $.50^{*}$ \\
\hline Sensation seeking & .91 & .20 & .30 & $.24^{*}$ & .41 & $.28^{*}$ & .29 & $.24^{*}$ & $.27^{*}$ \\
\hline Boredom Susceptibility & .71 & .20 & .09 & .04 & .48 & $.42^{*}$ & .28 & .15 & $.24^{*}$ \\
\hline Disinhibition & .81 & .30 & .13 & .13 & .46 & $.32^{*}$ & .41 & $.33^{*}$ & $.30^{*}$ \\
\hline Thrill and adventure seeking & .85 & .36 & .30 & $.32^{*}$ & .10 & .01 & .07 & .12 & $.10^{*}$ \\
\hline Experience seeking & .69 & .20 & .30 & $.30^{*}$ & .18 & .11 & .05 & .06 & $.11^{*}$ \\
\hline BAS drive & .83 & .55 & .20 & $.24^{*}$ & .16 & .03 & .23 & $.26^{*}$ & $.11^{*}$ \\
\hline BAS fun seeking & .76 & .44 & .11 & .20 & .12 & .06 & .37 & $.43^{*}$ & $.17^{*}$ \\
\hline BAS reward responsiveness & .82 & .48 & .07 & .14 & -.18 & $-.27^{*}$ & .04 & .16 & $.07^{*}$ \\
\hline Behavioral inhibition system & .66 & .22 & -.50 & $-.43^{*}$ & -.34 & $-.30^{*}$ & .06 & .05 & $.32 *$ \\
\hline
\end{tabular}

Note. Coefficients in bold were hypothesized. $r=1.231$ in the correctional sample was statistically significant at $p<.0008$. AIC $=$ Average Inter-Item Correction; BAS = Behavioral Activation System.

${ }^{*} p<.0008$.

\section{Discussion}

The current findings indicate that the triarchic psychopathy domains-boldness, meanness, and disinhibition-capture a substantial amount of variance in other psychopathy measures with various conceptual underpinnings, which supports many of Patrick et al.'s (2009) hypotheses. For instance, 51-75\% of variance was predicted in the PPI/PPI-R, LSRP, and APSD total scores, and these measurement modalities were associated with the three triarchic domains at conceptually expected relative degrees of association. Moreover, the EFA indicated that when psychopathy traits are considered at their most specific measurement level across the various instruments, they conform to a three-factor structure that closely matches the triarchic conceptualization.

As anticipated, the meanness and disinhibition domains explained variance in all of the psychopathy measures used in the current study. Meanness was predominantly associated with indices reflecting callous-unemotional traits, coldheartedness, egocentricity, and Machiavellianism. ${ }^{2}$ In contrast, disinhibition predicted the most variance in psychopathy subscales reflecting impulsivity and social deviance. These findings are not unexpected given that these measures (LSRP and APSD in particular) were developed to mirror the PCL-R (Frick \& Hare, 2001; Levenson et al., 1995), which primarily emphasizes the meanness and disinhibition domains of psychopathy (Patrick et al., 2009).

Boldness, however, was primarily present in the PPI/PPI-R measurement of psychopathy, particularly the fearless-dominance domain. Indeed, they are almost interchangeable — both conceptually and empirically. This emphasis separates the PPI/PPI-R from all other psychopathy measures and has even led some scholars to question whether this domain is relevant to psychopathy, mainly because most correlates tend to reflect adaptive functioning (Miller \& Lynam, 2011). An alternative perspective, with which we agree, is that the boldness domain emphasizes Cleckley's (1941/1976) positive adjustment characteristics that contribute to the "mask of sanity" that gives the appearance of good psychological functioning despite the severe behavioral pathology (see also Lilienfeld et al., in press). Moreover, fearlessness and dominance are associated with at least some forms of maladaptive behavior, including (but not limited to) a grandiose interpersonal style and engagement in highly dangerous activities for thrill seeking purposes despite considering the potential circumstances (Lykken, 1995), which were both supported in the current study.

The current findings also have theoretical implications for underlying temperaments associated with these phenotypic domains. Patrick et al. (2009) hypothesized that a fearless temperament could explain the overlap between the meanness and boldness domains. Indeed, our results from the female correctional sample indicate that both meanness and boldness were associated with low BIS, which represents a psychobiological motivation system that underlies fearlessness and has been linked to psychopathy (e.g., Lykken, 1995). In laboratory studies, deficiencies in fearresponding have been shown for both PCL-R Factor 1 scores (primarily meanness; e.g., Patrick, 1994) and PPI fearlessdominance scores (primarily boldness; e.g., Benning, Patrick, Blonigen, Hicks, \& Iacono, 2005a) using psychophysiology methods. Of course, this hypothesis requires further study with laboratory tasks before any conclusions are warranted.

Finally, the somewhat unexpected pattern of results with sensation seeking and BAS in the female correctional sample warrants some discussion. The associations for boldness with SSS experience seeking and BAS drive were larger (relative to other triarchic domains) than expected (e.g., Benning, Patrick, \& Iacono, 2005b). This can likely be explained by the strong correlation between boldness and positive emotionality, which is linked to psychobiological approach systems. Moreover, the pattern of associations for meanness and disinhibition with SSS disinhibition and boredom susceptibility also ran counter to

\footnotetext{
${ }^{2}$ It is noteworthy that the APSD Narcissism items reflect a manipulative and exploitative style in addition to grandiosity, which explains why meanness rather than boldness (which is more directly linked to actual narcissism) predicted the most variance in this measure.
} 
expectations. Research with the externalizing spectrum of psychopathology has, however, indicated a substantial loading for excitement seeking on a distinct (from general disinhibition) callous-aggression residual subfactor (Krueger et al., 2007), which has been used as a proxy for meanness (Venables \& Patrick, 2011).

Our current findings, however, must also be considered in light of some limitations. All constructs were indexed via self-report questionnaires, which introduces the possibility for inflation of effect size magnitudes due to shared method variance. However, this would be unlikely to affect the relative degrees to which the triarchic domains were associated with other psychopathy models. In terms of specific measurement concerns, some researchers have questioned the discriminant validity of the BIS subscale as an index of fearlessness (e.g., Poythress et al., 2008) as well as the LSRP factor scale scores as measures of primary psychopathy (Poythress et al., 2010). Future studies should incorporate other measurement modalities, including the PCL-R and its derivatives. Moreover, the incarcerated sample was limited to female participants, so these findings need to be replicated in male correctional samples as well. Finally, it would be important for future research to incorporate laboratory tasks to elaborate on putative etiological mechanisms underlying both the common and specific variances in the triarchic domains.

\section{References}

American Psychiatric Association. (1980). Diagnostic and statistical manual of mental disorders (3rd ed.). Washington, DC: Author.

Barry, C. T., Frick, P. J., DeShazo, T. M., McCoy, M. Ellis, M., \& Loney, B. R. (2000). The importance of callous-unemotional traits for extending the concept of psychopathy to children. Journal of Abnormal Psychology, 109, 335-340. doi:10.1037/0021-843X.109.2.335

Benning, S. D., Patrick, C. J., Blonigen, D. M., Hicks, B. M., \& Iacono, W. G., (2005a). Estimating facets of psychopathy from normal personality traits: A step toward community epidemiological investigations. Assessment, 12, 3-18. doi:10.1177/1073191104271223

Benning, S. D., Patrick, C. J., Hicks, B. M., Blonigen, D. M., \& Krueger, R. F. (2003). Factor structure of the Psychopathic Personality Inventory: Validity and implications for clinical assessment. Psychological Assessment, 15, 340-350. doi:10.1037/1040-3590.15.3.340

Benning, S. D., Patrick, C. J., \& Iacono, W. G. (2005b). Psychopathy, startle blink modulation, and electrodermal reactivity in twin men. Psychophysiology, 42, 753-762. doi:10.1111/j.1469-8986.2005.00353.x

Ben-Porath, Y. S., \& Tellegen, A. (2008). Minnesota Multiphasic Personality Inventory-2-Restructured form: Manual for administration, scoring, and interpretation. Minneapolis, MN: University of Minnesota Press.

Buss, A. H., \& Plomin, R. (1984). Temperament: Early developing personality traits (2nd ed.). Hillsdale, NJ: Erlbaum.

Caputo, A. A., Frick, P. J., \& Brodsky, S. L. (1999). Family violence and juvenile sexual offending: The potential mediating role of psychopathic traits and negative attitudes towards women. Criminal Justice and Behavior, 7, 193-199.

Carver, C. S., \& White, T. L. (1994). Behavioral inhibition, behavioral activation, and affective responses to impending reward and punishment: The BIS/BAS Scales. Journal of Personality and Social Psychology, 67, 319-333. doi:10.1037/0022-3514.67.2.319

Christie, R., \& Geis, F. L. (1970). Studies in Machiavellianism. New York, NY: Academic Press.
Cleckley, H. (1941/1976). The mask of sanity (5th ed.). St. Louis, MO C. V. Mosby.

Frick, P. J. (2004). The inventory of callous-Unemotional traits. Unpublished rating scale, University of New Orleans.

Frick, P. J., \& Hare, R. D. (2001). The antisocial processes screening device. Toronto, ON: Multi-Health Systems.

Hare, R. D. (1996). Psychopathy: A clinical construct whose time has come. Criminal Justice and Behavior, 23, 25-54. doi:10.1177/ 0093854896023001004

Hare, R. D. (2003). The Hare Psychopathy Checklist-Revised: 2nd Edition. Toronto, Ontario: Multi-Health Systems.

Jorm, A. F., Christensen, H. H., Henderson, A. S., Jacomb, P. A., Korten, A. E., \& Rodgers, B. (1999). Using the BIS/BAS scales to measure behavioural inhibition and behavioural activation: Factor structure, validity and norms in a large community sample. Personality and Individual Differences, 26, 49-58.

Karpman, B. (1941). On the need of separating psychopathy into two distinct clinical types: the symptomatic and the idiopathic. Journal of Criminal Psychopathology, 3, 112-137.

Kimonis, E. R., Frick, P. J., Skeem, J. L., Marsee, M. A., Cruise, K., Munoz, L. C., . . Morris, A. S. (2008). Assessing callous-unemotional traits in adolescent offenders: Validation of the inventory of callousunemotional traits. International Journal of Law and Psychiatry, 31, 241-252. doi:10.1016/j.ijlp.2008.04.002

Krueger, R. F., Markon, K. E., Patrick, C. J., Benning, S. D., \& Kramer, M. D. (2007). Linking antisocial behavior, substance use, and personality: An integrative quantitative model of the adult externalizing spectrum. Journal of Abnormal Psychology, 116, 645-666. doi:10.1037/ 0021-843X.116.4.645

Levenson, M. R., Kiehl, K. A., \& Fitzpatrick, C. M. (1995). Assessing psychopathic attributes in a non-institutionalized population. Journal of Personality and Social Psychology, 68, 151-158. doi:10.1037/00223514.68.1.151

Lilienfeld, S. O., \& Andrews, B. P. (1996). Development and preliminary validation of a self-report measure of psychopathic personality traits in noncriminal populations. Journal of Personality Assessment, 66, 488524. doi:10.1207/s15327752jpa6603_3

Lilienfeld, S. O., Patrick, C. J., Benning, S. D., Berg, J., Sellbom, M., \& Edens, J. F. (in press). The role of fearless dominance in psychopathy: Confusions, clarifications, and fruitful new directions. Personality Disorders: Theory, Research, and Treatment.

Lilienfeld, S. O., \& Widows, M. R. (2005). Psychopathic personality inventory-Revised professional manual. Lutz, FL: Psychological Assessment Resources, Inc.

Lykken, D. T. (1995). The antisocial personalities. Mahwah, NJ: Erlbaum.

Marcus, D. K., Fulton, J. J., \& Edens, J. F. (2012). The two-factor model of psychopathic personality: Evidence from the Psychopathic Personality Inventory. Personality Disorders: Theory, Research, and Treatment, 3, 140-154. doi:10.1037/a0025282

McCord, W., \& McCrod, J. (1964). The psychopathy: An essay of the criminal mind. New York, NY: Van Nostrand Reinhold.

Mehrabian, A., \& Epstein, N. (1972). A measure of emotional empathy. Journal of Personality, 40, 525-543. doi:10.1111/j.1467-6494.1972 .tb00078.x

Miller, J. D., \& Lynam, D. R. (2011). An examination of the Psychopathic Personality Inventory's nomological network. A meta-analytic review. Personality Disorders: Theory, Research, and Treatment. Advanced online publication.

Neal, T. M. S., \& Sellbom, M. (2012). Examining the factor structure of the Hare Self-Report Psychopathy Scale. Journal of Personality Assessment 94, 244-253. doi:10.1080/00223891.2011.648294

Neumann, C. S., Malterer, M. B., \& Newman, J. P. (2008). Factor structure of the Psychopathic Personality Inventory (PPI): Findings from a large 
incarcerated sample. Psychological Assessment, 20, 169-174. doi: 10.1037/1040-3590.20.2.169

Patrick, C. J. (1994). Emotion and psychopathy: Startling new insights. Psychophysiology, 31, 319-330. doi:10.1111/j.1469-8986.1994 .tb02440.x

Patrick, C. J. (2006). The handbook of psychopathy. New York, NY: Guilford Press.

Patrick, C. J. (2010a). Conceptualizing the psychopathic personality: Disinhibited, bold, ... Or just plain mean? In R. T. Salekin \& D. R. Lynam (Eds.), Handbook of child adolescent psychopathy (pp. 15-48). New York, NY: Guilford Press.

Patrick, C. J. (2010b). Triarchic psychopathy measure (TriPM). PhenX Toolkit Online Assessment Catalog. Retrieved from https://www.phenxtoolkit .org/index.php?pageLink = browse.protocol details\&id $=121601$

Patrick, C. J., Fowles, D. C., \& Krueger, R. F. (2009). Triarchic conceptualization of psychopathy: Developmental origins of disinhibition, boldness, and meanness. Development and Psychopathology, 21, 913938. doi:10.1017/S0954579409000492

Paulhus, D. L., \& Williams, K. M. (2002). The Dark Triad of personality: Narcissism, Machiavellianism and psychopathy. Journal of Research in Personality, 36, 556-563. doi:10.1016/S0092-6566(02)00505-6

Poythress, N. G., Edens, J. F., Landfield, K., Lilienfeld, S. O., Skeem, J. L., \& Douglas, K. S. (2008). A critique of Carver and White's (1994) Behavioral Inhibition Scale (BIS) for investigating Lykken's (1995) theory of primary psychopathy. Personality and Individual Differences, 45, 269-275. doi:10.1016/j.paid.2008.04.014

Poythress, N. G., Lilienfeld, S. O., Skeem, J. L., Douglas, K. S., Edens, J. F., Epstein, M., \& Patrick, C. J. (2010). Using the PCL-R to help estimate the validity of two self-report measures of psychopathy with offenders. Assessment, 17, 206-219. doi:10.1177/1073191109351715

Raskin, R., \& Terry, H. (1988). A principal-components analysis of the Narcissistic Personality Inventory and further evidence of its construct validity. Journal of Personality and Social Psychology, 54, 890-902. doi:10.1037/0022-3514.54.5.890

Sellbom, M. (2011). Elaborating on the Construct Validity of the Levenson Self-Report Psychopathy Scale in Incarcerated and Non-Incarcerated Samples. Law and Human Behavior, 35, 440-451. doi:10.1007/s10979010-9249-x

Venables, N. C., \& Patrick, C. J. (2011). Validity of the externalizing spectrum inventory in a criminal offender sample: Relations with disinhibitory psychopathology, personality, and psychopathic features. Psychological Assessment. Advance online publication. doi:10.1037/ a0024703

Received November 18, 2011

Revision received June 7, 2012

Accepted June 7, 2012 